\title{
Contribution of Body Mass Index to Postoperative Outcome in Minority Patients
}

\author{
Olubukola O. Nafiu, MD, Satya Krishna Ramachandran, MD, Deborah S. Wagner, PharmD", \\ Darrell A. Campbell Jr, MD², James C. Stanley, MD²
}

${ }^{1}$ Department of Anesthesiology, University of Michigan, Ann Arbor, Michigan; ²Department of Surgery, University of Michigan, Ann Arbor, Michigan.

OBJECTIVE: The purpose of this investigation was to examine the association of body mass index (BMI) category with short-term outcomes in minority surgical patients-a relationship that previously has not been well characterized.

METHODS: Data from the National Surgical Quality Improvement Program were used to calculate the BMI of minority patients undergoing surgery from 2005 to 2008. Patients were stratified into $5 \mathrm{BMI}$ classes. Stepwise logistic regression was used to calculate odds ratios for mortality after controlling for known clinically relevant covariates.

MAIN OUTCOME MEASURES: Morbidity and mortality at 30 days, across all $5 \mathrm{BMI}$ classes.

RESULTS: Among 119,619 minority patients studied, 50\% were African American, 36\% Hispanic, 10\% Asian and Pacific Islanders, and 4\% American Indian and Alaskan natives. Seventy percent were overweight or obese.
Women were more likely to be obese or severely obese. The overall mortality rate was $1.5 \%$, and this varied significantly by BMI class. Distribution of 30-day mortality demonstrated a progressive decrease, with the highest risk of death in the underweight class, and the lowest risk of death in the severely obese class. This relationship was maintained, even in patients with at least 1 major postoperative complication.

CONCLUSION: The prevalence of being overweight or obese was high in this nationally representative cohort of minority surgical patients. Although BMI class is a significant predictor of 30-day mortality, the effect appeared paradoxical. The poorest outcomes were in the underweight and normal BMl patients. Severely obese patients had the lowest risk of mortality, even after experiencing a major postoperative complication. Journal of Hospital Medicine 2012;7:117-123 (C) 2011 Society of Hospital Medicine.
Obesity affects all segments of the American population. However, it imposes a larger burden and poses a greater threat to minority populations. ${ }^{1}$ The increase in overall prevalence of obesity and obesity-related diseases are especially pronounced in ethnic minorities, ${ }^{2}$ and the outlook for minorities who develop obesity-associated diseases such as stroke and chronic renal disease is worse than in their Caucasian counterparts. $^{3}$

Despite the higher prevalence of obesity in ethnic minorities, the majority of research on the relationship between body mass index (BMI) and mortality has been conducted among Caucasians in the United States. This is due largely to the small number of minority participants in most studies, which makes for low statistical power. ${ }^{4}$

A curious epidemiologic paradox has been the observation, in many studies, that black adults have

\footnotetext{
*Address for correspondence and reprint requests: Olubukola $\mathrm{O}$. Nafiu, MD, Department of Anesthesiology, University of Michigan Health System, 1500 East Medical Centre Dr, Room UH 1H247, Ann Arbor, Ml 48109-0048; Tel.: 734-936-4280; E-mail: onafiu@med.umich.edu Additional Supporting Information may be found in the online version of this article.

Received: February 16, 2011; Revised: May 29, 2011; Accepted: June 15,2011

2011 Society of Hospital Medicine DOI 10.1002/jhm.958

Published online in Wiley Online Library (Wileyonlinelibrary.com).
}

lower morbidity and mortality associated with obesity compared to Caucasians. ${ }^{5}$ In fact, some authors suggest that high BMI among black and other minorities may not be as strong a risk factor for mortality as it is in others. ${ }^{6,7}$

Very few studies have specifically examined the contribution of BMI to postoperative outcome in a large cohort of minority patients. ${ }^{8,9}$ Similarly, the authors are unaware of any previous studies describing the clinical relevance of being overweight and obese in minority patients undergoing surgery. Therefore, the primary objective of this observational study was to describe the prevalence of overweight and obesity in a large cohort of minority surgical patients, and the impact of BMI class on their postoperative outcome. Our a priori hypothesis was that obese minority surgical patients would have a poorer postoperative outcome and have higher 30-day all-cause mortality than normal weight individuals.

\section{METHODS}

Study data were derived from the Participant Use Data File of the American College of Surgeons (ACS) National Surgical Quality Improvement Program (NSQIP) for the calendar years 2005 to 2008. This multi-institutional (186 participating centers) reporting system was designed to provide risk-adjusted surgical outcome data from throughout the United States. 
The methodology for collecting these data, including their accuracy and reproducibility, has been detailed in previous publications. ${ }^{10,11}$ It is briefly reviewed here. Dedicated nurse clinical reviewers at each hospital prospectively enrolled patients and collected data in a standardized fashion according to strict ACS-NSQIP definitions. A systematic sample was obtained by taking the first 40 cases per nurse reviewer on an 8-day cycle from the operating room log, ensuring that no particular operating room day block time would bias the weighting of cases. Nurse reviewers had completed comprehensive training regarding definitions and data extraction, as well as continuing education and monitoring through the ACS-NSQIP program. They are assessed for inter-rater reliability during biennial site visits. Information was obtained from patient medical records, physician office records, and telephone interviews. Patients were followed through their hospital course and after discharge from hospital up to 30 days postoperatively. A high level of accuracy and reproducibility of the data have been previously demonstrated. ${ }^{12}$

Race was defined as African American, Hispanic, Asian or Pacific Islander, or American Indian/Alaskan native, as identified by the clinical care provider, or within the medical record. Patients were excluded if race was coded as white, or not recorded. We also excluded patients with missing record of height and/or weight. The final study cohort consisted of 119,619 minority patients. We then computed BMI as weight in kilograms divided by the square of the height in meters $\left(B M I=\mathrm{kg} / \mathrm{m}^{2}\right)$. Patients were classified as underweight (BMI $\leq 18.5 \mathrm{~kg} / \mathrm{m}^{2}$ ), normal weight (BMI $\left.=18.6-24.9 \mathrm{~kg} / \mathrm{m}^{2}\right)$, overweight $(\mathrm{BMI}=25-29.9 \mathrm{~kg} /$ $\mathrm{m}^{2}$ ), obese $\left(\right.$ BMI $\left.=30-39.9 \mathrm{~kg} / \mathrm{m}^{2}\right)$, and morbidly obese (BMI $\geq 40 \mathrm{~kg} / \mathrm{m}^{2}$ ) in accordance with National Institute of Health (NIH) standards. ${ }^{13}$

\section{Outcomes}

The primary outcome was death within 30 days of the index surgery. Secondary outcomes were the occurrence of major or minor complications. Major complications were grouped as the occurrence of at least one of following: organ space infection, wound disruption, sepsis or septic shock, bleeding requiring transfusion, postoperative pneumonia, delayed ventilator wean, unplanned reintubation, myocardial infarction, deep venous thrombosis, cardiac arrest, coma, acute renal failure, progressive renal insufficiency, and return to the operating room. We then computed a composite morbidity variable defined as the occurrence of 1 or more of these major postoperative complications. Minor complications included occurrence of urinary tract infection, superficial surgical site infection, and superficial thrombophlebitis.

\section{Statistical Analysis}

Data analysis was carried out with SPSS v.16.0 (SPSS, Chicago, IL). Basic descriptive statistics, including means, standard deviations, and percentages were calculated for demographic and anthropometric data. Prevalence of overweight and obesity were described as simple proportions and compared along gender lines. Pearson's chi-square analysis of categorical variables and 1-way ANOVA of continuous variables were used to examine baseline clinical and perioperative differences between BMI categories. Pair-wise comparisons, with the normal BMI class serving as the reference, were performed using the Bonferroni multiple comparison of means method. The overall mortality rate was calculated as well as the distribution of mortality across BMI classes. We also compared mortality rate in patients who developed at least 1 major postoperative complication-defined as failure to rescue ${ }^{14}$ across the BMI classes.

Multivariate logistic regression models were fitted to the data to explore the relationship between BMI category and death within 30 days of surgery. Odds ratios for 30-day all-cause mortality were calculated in the BMI categories using the normal BMI group as reference. The following characteristics were included in the model as covariates based on a priori statistical significance or clinical relevance: age $(<65$ years vs $\geq 65$ years), American Society of Anesthesiology (ASA) status (I-II vs $\geq \mathrm{III}$ ), racial groups, and urgency of surgery (elective vs emergent). Other covariates included the presence of multiple medical conditions (coded as yes or no), surgical complexity, need for reoperation, reintubation, and preoperative functional status. A model fit was measured with the Hosmer and Lemeshow test. ${ }^{15}$ All reported $P$ values were 2 sided and a $P$ value of 0.05 was considered to be significant.

\section{RESULTS}

The study cohort included 119,619 surgical patients (Table 1). Their mean (standard deviation [SD]) age was 50.4 (16.9), and the mean (SD) BMI of 30.3 (8.9) $\mathrm{kg} / \mathrm{m}^{2}$ was in the obese range. The overall prevalence of high BMI (overweight or obese) was $70.8 \%$. A very small proportion, $2.7 \%$, of patients was classified as underweight. Sex-stratified demographic and behavioral characteristics differed significantly across all the variables in our study cohort. Men were more likely to be overweight, whereas women were more likely to be obese or severely obese. A majority $(77.4 \%)$ of the patients were non-elderly adults $(<65$ years $)$ undergoing elective $(85.9 \%)$ surgical procedures. The minority patients in this study were African American (50\%), Hispanic (36\%), Asian and Pacific Islander $(10 \%)$, and American Indian and Alaskan native $(4 \%)$.

The distribution of baseline preoperative clinical characteristics by BMI class revealed many significant differences (Table 2). Age was significantly different among the BMI classes, with the severely obese group being about 8 years younger than the underweight or 
normal weight group. Similarly, severely obese patients were more likely to be women, less likely to smoke, more likely to be hypertensive, diabetic, have a history of dyspnea at rest, and more likely to belong to high ASA class. On the other hand, underweight patients were more likely to have disseminated cancer,

\begin{tabular}{lllll}
\hline \multicolumn{5}{l}{ TABLE 1. Baseline Demographic Characteristics } \\
Including Major Surgical Specialties of a Minority \\
Surgical Population \\
Baseline & All Patients & Men & Women & \\
Characteristics & $(\mathrm{N}=119,619)$ & $(\mathrm{N}=44,922)$ & $(\mathrm{N}=74,695)$ & P Value \\
\hline Age (yr) & $50.4 \pm 16.9$ & $51.6 \pm 17.1$ & $49.6 \pm 16.7$ & $<0.001$ \\
Age $\geq 65$ yr & 22.6 & 25.5 & 20.8 & $<0.001$ \\
Current smoker & 22.2 & 28.8 & 18.2 & $<0.001$ \\
$>2$ Drinks/day & 37.6 & 4.1 & 0.8 & $<0.001$ \\
BMl & $30.3 \pm 8.8$ & $28.4 \pm 7.3$ & $31.4 \pm 9.5$ & $<0.001$ \\
Underweight & 2.7 & 2.9 & 2.6 & 0.001 \\
Overweight & 29.2 & 35.5 & 25.4 & $<0.001$ \\
Obese & 28.8 & 24.9 & 31.2 & $<0.001$ \\
Severely obese & 12.8 & 6.2 & 16.8 & $<0.001$ \\
Ethnic categories & & & & \\
Black & 50.4 & 48.0 & 51.7 & $<0.001$ \\
Hispanic & 36.2 & 38.2 & 35.2 & $<0.001$ \\
Asian* & 9.7 & 10.3 & 9.3 & $<0.001$ \\
American Indian ${ }^{\dagger}$ & 3.6 & 3.5 & 5.8 & $<0.001$ \\
Surgical specialties & & & & \\
General surgery & 77.9 & & & \\
Vascular surgery & 10.3 & & & \\
Orthopedics & 4.0 & & & \\
Gynecology & 3.4 & & & \\
Urology & 1.1 & & & \\
Others & 3.3 & & & \\
\end{tabular}

NOTE: All values are percentages unless otherwise stated. Abbreviation: BMI, body mass index. *Includes Asians and Pacific Islanders. ${ }^{\dagger}$ Includes American Indians and Alaskan natives. be current smokers, consume more than 2 alcoholic drinks per day, have active chronic obstructive pulmonary disease (COPD), and have ascites. They were also more likely to be on dialysis and have cardiac disease, as well as a history of stroke. Urgency of surgery also varied significantly across the BMI categories, with the underweight group having the highest incidence of emergency surgery $(20.6 \%)$ and the severely obese group being the least likely to present for emergency surgery $(8.2 \%)$.

Perioperative outcomes according to BMI classes documented significant differences (Table 3). Work relative value unit (Work RVU, a measure of surgical complexity), as well as total anesthesia and operation time decreased in a stepwise fashion across the BMI classes to the obese group, followed by increase in these parameters in the severely obese group. Following a decrease to the normal BMI category, there was a positive association between BMI and the incidence of postoperative superficial and deep wound infection, as well as wound disruption.

There was a negative association between BMI class and the likelihood of postoperative sepsis, septic shock, reintubation, delayed ventilator wean, and postoperative pneumonia. Similarly, the proportions of patients who developed postoperative acute renal failure, cardiac arrest, and those who required postoperative blood transfusion or needed reoperation, decreased significantly across the BMI classes, with the highest proportion of cases being in the underweight group and the lowest in the severely obese group. Overall composite morbidity was twice as high in the underweight compared to the severely obese group.

\begin{tabular}{|c|c|c|c|c|c|c|}
\hline \multirow{2}{*}{$\begin{array}{l}\text { BMl range }\left(\mathrm{kg} / \mathrm{m}^{2}\right) \\
\text { Characteristics }\end{array}$} & \multicolumn{5}{|c|}{ Mean $\pm \mathrm{SD}$ or $(\%)$} & \multirow[b]{2}{*}{$P$ Value } \\
\hline & UW ( $\leq 18.5)$ & NW (18.5-24.9) & OVW (25-29.9) & $\mathrm{OB}(30-39.9)$ & $\operatorname{SevOB}(\geq 40)$ & \\
\hline Age (yr) & $53.4 \pm 19.3$ & $51.1 \pm 18.4$ & $51.8 \pm 16.9$ & $50.4 \pm 15.5$ & $45.2 \pm 13.4$ & $<0.001$ \\
\hline Female & 59.8 & 56.7 & 54.4 & 67.5 & 81.7 & $<0.001$ \\
\hline Current smoker & 32.1 & 25.6 & 22.1 & 20.4 & 17.1 & $<0.001$ \\
\hline$>2$ Drinks/day & 4.1 & 2.7 & 2.2 & 1.6 & 0.7 & $<0.001$ \\
\hline Hypertension & 41.7 & 38.4 & 44.0 & 51.0 & 56.0 & $<0.001$ \\
\hline DM (insulin or oral agents) & 12.5 & 13.1 & 16.4 & 22.3 & 26.3 & $<0.001$ \\
\hline COPD & 7.7 & 3.3 & 2.5 & 2.7 & 2.5 & $<0.001$ \\
\hline Dyspnea at rest & 10.5 & 7.1 & 7.2 & 9.9 & 20.2 & $<0.001$ \\
\hline$A S A \geq\|\mid\|$ & 59.0 & 39.5 & 35.6 & 39.8 & 62.2 & $<0.001$ \\
\hline Emergency surgery & 20.6 & 17.6 & 15.2 & 11.9 & 8.2 & $<0.001$ \\
\hline Active CHF & 2.2 & 1.3 & 1.1 & 1.1 & 1.1 & $<0.001$ \\
\hline Recent Ml & 1.1 & 0.8 & 0.8 & 0.6 & 0.4 & $<0.001$ \\
\hline Recent angina & 1.2 & 1.1 & 1.1 & 1.2 & 0.7 & $<0.001$ \\
\hline Disseminated cancer & 4.3 & 2.5 & 1.6 & 1.3 & 0.6 & $<0.001$ \\
\hline Recent $\geq 10 \%$ weight loss & 15.2 & 4.2 & 1.7 & 1.0 & 0.5 & $<0.001$ \\
\hline Ascites & 4.4 & 2.1 & 1.2 & 0.9 & 0.5 & $<0.001$ \\
\hline Currently on dialysis & 9.7 & 6.7 & 4.9 & 4.1 & 2.9 & $<0.001$ \\
\hline Stroke history & 5.6 & 3.5 & 2.9 & 2.6 & 1.3 & $<0.001$ \\
\hline
\end{tabular}

NOTE: Emergency surgery was considered to exist when the anesthesiologist and the attending surgeon document a case to be "emergent" in the anesthesia record and the operative report. Abbreviation: ASA, American Society of Anesthesiologists; BMl, body mass index; CHF, congestive heart failure; COPD, chronic obstructive pulmonary disease; DM, diabetes mellitus; MI, myocardial infarction; NW, normal weight; OB, obese; OVW, overweight; SD, standard deviation; SevOB, severely obese; UW, underweight. 
TABLE 3. Perioperative Outcomes According to BMI Categories

\begin{tabular}{|c|c|c|c|c|c|c|}
\hline \multirow{2}{*}{$\begin{array}{l}\text { BMl }\left(\mathrm{kg} / \mathrm{m}^{2}\right) \\
\text { Events }\end{array}$} & \multicolumn{5}{|c|}{ Mean \pm SD or (\%) } & \multirow[b]{2}{*}{$P$ Value } \\
\hline & $\overline{\mathrm{UW}}(\leq 18.5)$ & NW (18.5-24.9) & OVW (25-29.9) & OB (30-39.9) & $\operatorname{SevOB}(\geq 40)$ & \\
\hline Work RVU & $16.3 \pm 9.5$ & $14.5 \pm 9.1$ & $14.0 \pm 8.4$ & $13.8 \pm 7.9$ & $17.3 \pm 9.1$ & $<0.001$ \\
\hline Anesthesia time (hr) & $2.7 \pm 1.9$ & $2.5 \pm 1.7$ & $2.5 \pm 1.6$ & $2.5 \pm 1.6$ & $2.7 \pm 1.5$ & $<0.001$ \\
\hline Pre-incision time (min) & $35.9 \pm 21.3$ & $33.1 \pm 21.1$ & $33.2 \pm 22.5$ & $32.5 \pm 19.3$ & $34.9 \pm 21.1$ & $<0.001$ \\
\hline Operation time (hr) & $1.8 \pm 1.6$ & $1.6 \pm 1.4$ & $1.7 \pm 1.4$ & $1.7 \pm 1.4$ & $1.8 \pm 1.2$ & $<0.001$ \\
\hline Transfused intra-op & 12.8 & 7.1 & 5.3 & 4.4 & 2.9 & $<0.001$ \\
\hline Superficial wound SSI & 2.9 & 2.5 & 2.6 & 2.8 & 3.1 & $<0.001$ \\
\hline Deep wound SSI & 1.5 & 0.7 & 0.8 & 0.9 & 1.0 & $<0.001$ \\
\hline Wound disruption & 1.5 & 0.6 & 0.6 & 0.6 & 0.7 & $<0.001$ \\
\hline Post-op sepsis & 5.7 & 2.9 & 2.2 & 2.1 & 2.0 & $<0.001$ \\
\hline Septic shock & 3.1 & 1.7 & 1.3 & 1.2 & 1.1 & $<0.001$ \\
\hline Reintubation & 3.8 & 1.8 & 1.2 & 1.0 & 1.0 & $<0.001$ \\
\hline Delayed ventilator wean & 5.5 & 2.8 & 2.1 & 2.0 & 2.0 & $<0.001$ \\
\hline Pneumonia & 4.3 & 2.1 & 1.3 & 1.2 & 1.2 & $<0.001$ \\
\hline Cardiac arrest/CPR & 1.5 & 0.7 & 0.5 & 0.4 & 0.4 & $<0.001$ \\
\hline Urinary tract infection & 3.4 & 1.8 & 1.5 & 1.6 & 1.6 & $<0.001$ \\
\hline Post-op ARF & 2.1 & 1.1 & 0.8 & 0.9 & 0.7 & $<0.001$ \\
\hline Return to OR & 11.2 & 6.9 & 5.8 & 5.5 & 4.9 & $<0.001$ \\
\hline Post-op coma & 0.4 & 0.2 & 0.1 & 0.1 & 0.1 & $<0.001$ \\
\hline Post-op transfusion & 1.6 & 0.7 & 0.5 & 0.4 & 0.5 & $<0.001$ \\
\hline Composite morbidities & 25.2 & 15.3 & 13.0 & 12.8 & 12.1 & $<0.001$ \\
\hline
\end{tabular}

NOTE: Work relative value unit (Work RVU) is a scale (0-95) to quantify the amount of work involved in a specific surgery based on pre-procedural, intra-procedural, and post-procedural time; technical skill; physical effort; mental effort and judgment; and stress due to potential risk. It is the work portion of the resource-based Relative Value System adopted by Medicare to quantify the amount of work involved in each medical procedure. A score of $0=$ least complex, and $95=$ most complex.

Abbreviations: ARF, acute renal failure; BMl, body mass index; CPR, cardiopulmonary resuscitation; NW, normal weight; OB, obese; OR, operating room; OVW, overweight; SD, standard deviation; SevOB, severely obese; SSI, surgical site infection; UW, underweight.

Underweight $\mathbf{n}$ Normal BMI $\mathbb{N}$ Overweight

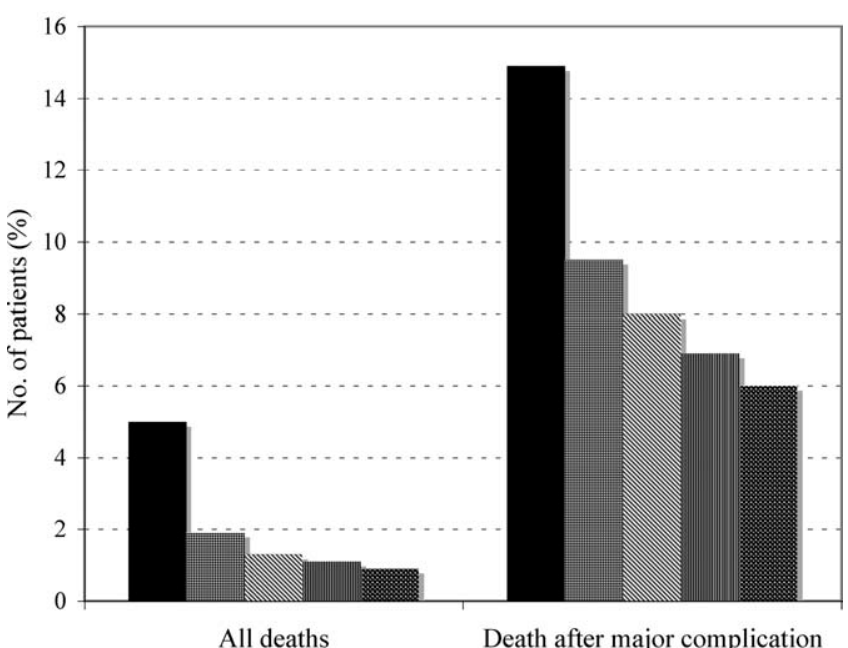

FIG. 1. All-cause death rate and death after at least 1 major complication stratified by BMI categories. There was progressive stepwise decrease in mortality across the BMI categories even in the presence of 1 or more major postoperative complication. Death rate increased significantly across all of the BMl group with the occurrence of 1 or more major postoperative complication, although the increase was least pronounced in the higher BMI categories. Abbreviation: BMI, body mass index.

There were 1758 deaths among the study's 119,619 patients, resulting in an overall mortality rate of $1.5 \%$. The overall major complication rate was $13.8 \%$. The distribution of total mortality rate as well as mortality in patients with at least 1 major postoperative complication across BMI classes revealed consistent differences (Figure 1). Over the entire range of
BMI classes, there was a progressive, stepwise decrease in the proportion of deaths with increasing BMI. This pattern also occurred among patients who developed at least 1 major postoperative complication, indicating a reduced likelihood of death after a major complication. This is reflective of a reduced likelihood of death after a major complication (failure to rescue) with increasing BMI.

Multivariate logistic regression defined a number of factors associated with 30-day mortality (Table 4). The Hosmer and Lemeshow goodness-of-fit test for this model was not statistically significant $\left(\chi^{2}=17.8\right.$, $d f=8, P=0.23)$. High ASA physical status was associated with high odds of mortality. Specifically, when controlling for the other covariates in the model, ASA status was associated with a 5 -fold increased relative odds of death (adjusted odds ratio $[\mathrm{OR}]=5.30 ; 95 \%$ confidence interval $=4.96-5.79, P<0.001)$. Similarly, occurrence of 1 or more major postoperative complication was associated with 6-fold increased relative odds of mortality. The paradoxical effect of BMI category observed on univariate analysis was maintained in the multivariate model. Specifically, underweight patients had the highest relative odds of mortality, while severely obese patients had the lowest, compared with patients at a healthy weight (Table 4). Interestingly, smoking had no significant effect on the odds of mortality after controlling for other factors. Similarly, the specific racial group and the timing of the surgical intervention had no significant effect on mortality. 
TABLE 4. Predictors of 30-Day Mortality Derived From Logistic Regression Performed on 119,619 Minority Surgical Patients

\begin{tabular}{|c|c|c|c|c|c|}
\hline $\begin{array}{l}\text { Variables in } \\
\text { the equation }\end{array}$ & $\begin{array}{l}\text { Coefficient } \\
\text { (B) }\end{array}$ & $\begin{array}{l}\text { Wald } \\
\left(\chi^{2}\right)\end{array}$ & $P$ Value & $\begin{array}{l}\text { Odds } \\
\text { Ratio }\end{array}$ & $95 \% \mathrm{Cl}$ \\
\hline ASA status $\geq \|||$ & 1.67 & 233.0 & $<0.001$ & 5.31 & $4.96-5.79$ \\
\hline Emergency operation & 0.89 & 241 & $<0.001$ & 2.43 & $2.17-2.72$ \\
\hline Reoperation & 0.77 & 155.9 & $<0.001$ & 2.10 & $1.91-2.44$ \\
\hline Reintubation & 0.4 & 51.4 & $<0.001$ & 1.63 & $1.41-1.82$ \\
\hline Dependent functional status & 1.2 & 422.5 & $<0.001$ & 3.44 & $3.01-3.79$ \\
\hline Cumulative comorbidity* & 0.09 & 12.37 & $<0.001$ & 1.18 & $1.03-1.14$ \\
\hline Major POP complication ${ }^{\dagger}$ & 1.8 & 686.1 & $<0.001$ & 6.43 & $5.59-7.39$ \\
\hline Age $\geq 65 \mathrm{yr}$ & 0.56 & 95.3 & $<0.001$ & 1.75 & $1.56-1.96$ \\
\hline Work RVU & 0.17 & 49.7 & $<0.001$ & 1.02 & $1.01-1.02$ \\
\hline Severely obese & Reference & & & 1.00 & \\
\hline Underweight & 0.76 & 30.9 & $<0.001$ & 2.13 & $1.63-2.78$ \\
\hline Normal BMI & 0.42 & 15.4 & $<0.001$ & 1.52 & $1.23-1.87$ \\
\hline Overweight & 0.28 & 6.9 & 0.009 & 1.33 & $1.08-1.65$ \\
\hline Obese & 0.19 & 2.86 & 0.091 & 1.20 & $0.97-1.49$ \\
\hline Dyspnea & 0.41 & 40.0 & $<0.001$ & 1.51 & $1.33-1.72$ \\
\hline Active CHF & 0.60 & 39.6 & $<0.001$ & 1.83 & $1.52-2.21$ \\
\hline Chronic renal failure (dialysis) & 0.70 & 102.2 & $<0.001$ & 2.01 & $1.76-2.30$ \\
\hline
\end{tabular}

Abbreviations: ASA, American Society of Anesthesiologists; BMI, body mass index; $\mathrm{CHF}$, congestive heart failure; $\mathrm{Cl}$, confidence interval; Work RVU, Work relative value unit.

${ }^{*}$ Cumulative comorbidity refers to the presence of 3 or more medical diagnoses.

${ }^{\dagger}$ Major POP complication indicates the occurrence of 1 or more major postoperative complication.

\section{DISCUSSION}

In this large, study of minority surgical patients, the impact of BMI on the 30-day morbidity and mortality was unexpected. The working hypothesis was that overweight and obese patients would have a worse outcome after surgery. However, contrary to this hypothesis, the lowest all-cause mortality rate was found in the severely obese (BMI $\geq 40 \mathrm{~kg} / \mathrm{m}^{2}$ ) group in both men and women. Death rates decreased progressively in a stepwise fashion from the underweight to the severely obese group. Similarly, even in patients who developed at least 1 major postoperative complication, the likelihood of death was still negatively associated with BMI. This negative association of mortality with BMI was observed despite the higher prevalence of chronic diseases, such as hypertension, diabetes, and dyspnea at rest, in the increasing BMI classes.

Controversy remains regarding the association between BMI and mortality, in particular about the shape of the curve for the association between BMI and mortality. Epidemiologic studies have variously described J-shaped, U-shaped, monotonic, or linear relationships. ${ }^{16,17}$ In the surgical population, a reverse J-shaped relationship between BMI category and mortality has been described. ${ }^{18,19}$ Sometimes this is referred to as "obesity paradox" or reverse epidemiology: a trend whereby overweight and moderately obese patients have better outcomes and lower risk of death than leaner patients. ${ }^{18}$ This phenomenon is particularly well described in adult ${ }^{20}$ and elderly heart failure and hypertensive patients. ${ }^{21}$ Many of these studies either had very few minority patients, ${ }^{21}$ or mortality pattern was not analyzed along ethnic lines.
Few studies ${ }^{10}$ have focused exclusively on minority surgical patients. Some investigators have determined that high BMI in black adults may not be as important a risk factor for mortality ${ }^{6,7}$ as in whites. Our data suggest that among minority surgical patients, the relationship appeared to be a downward trend in mortality from low to high BMI, thus revealing the obesity paradox. This pattern was evident even in patients who developed 1 major complication in the postoperative period, suggesting that high BMI also protects against "failure to rescue"- - or death after a major complication.

Despite decades of research, the mechanisms underlying the obesity paradox remain speculative. ${ }^{20,22}$. Many have posited that adiposity may confer protection against cytokines and various inflammatory mediators in heart failure patients by the production of "buffering" lipoproteins. ${ }^{23,24}$ It is conceivable that similar protection against inflammatory response to surgical tissue trauma is operational in minority patients with high BMI. Another possible reason for the obesity paradox is the clinical presentation and disease progression at the time of surgery. Perhaps, similar to the observation in obese patients with heart failure, ${ }^{25}$ obese minority patients are symptomatic at an earlier stage of their disease than lean patients, making for earlier diagnosis and treatment. Thus, obesity may simply be a marker of less severe disease at the time of presentation.

Obese patients may also be more aggressively monitored and treated in the perioperative period than lean patients, because of the general perception that they are a high-risk group. ${ }^{10}$ This may partly explain the decreased likelihood of "failure to rescue" with increasing BMI in our patients. Increased vigilance and prompt treatment of complications should reduce the overall morbidity and mortality rate in this group. It is also conceivable that a "therapeutic selection bias" is operational in the patients we studied. This describes scenarios where relatively healthy obese minority patients were operated upon, while sicker, morbidly obese patients were denied surgery due to perceived prohibitive risks. However, we would have expected a higher proportion of severely obese patients to present for emergency surgery, which is contrary to our finding of the lowest incidence of emergency surgery in the severely obese group. It is also possible that severe obesity may be associated with a higher attrition rate, such that the extremely obese patients did not live long enough to present for surgery. This is somewhat likely, given the significantly younger age of the severely obese patients in our study cohort. It is, however, impossible to determine survival effect from a cross-sectional hospital-based study design. Clearly, mechanisms used to explain the obesity paradox in minority surgical patients are likely to remain speculative, owing to the interaction of several factors such as concomitant comorbidities, disease progression at the time of 
presentation, patients' weight history, and regional fat distribution.

The current study confirms the findings of previous investigators ${ }^{26}$ about the importance of reducing major postoperative complications in surgical patients. While this may seem axiomatic, it deserves reiteration because the risk of postoperative mortality increases considerably in all the BMI categories following 1 or more major postoperative complication. However, it is not clear why obese and morbidly obese patients had a lower incidence of "failure to rescue." This may be related to greater physiologic reserve in the obese and morbidly obese group, especially because patients in the higher BMI groups were significantly younger than the normal weight or lean patients. For the same reason, these younger, severely obese patients may have been more aggressively monitored and treated, thereby increasing the likelihood of being "rescued" following a major complication. It is also possible that the lower proportion of emergency procedures performed in obese and severely obese groups was somewhat protective, especially because emergency surgery was an independent predictor of overall mortality in this cohort of patients. In fact, when we stratified the patients according to urgency of surgery and explored the bivariate relationship between BMI category and mortality (data not shown) among those undergoing urgent surgery, the geometrical distribution of mortality did show a reverse-J pattern with the highest proportion of cases in the underweight group, declining in the normal BMI and overweight group, and increasing steadily in obese and severely obese group. To this end, caution should be exercised when interpreting the association of BMI group with postoperative mortality for procedures performed as an emergency.

Smoking and antecedent illness are 2 confounding factors commonly criticized in studies attempting to associated BMI with mortality. This is because smokers tend to weigh less and have higher mortality rates than nonsmokers. The present investigation did not find a significant contribution of smoking to mortality when other factors included in a logistic regression model were considered. The current study's findings are consistent with those of previous data in African American patients, ${ }^{27}$ and contrasts with the excess mortality described in currently smoking Caucasian men and women. ${ }^{28}$ It is possible that smoking is not an important effect modifier when considering the relevance of BMI to postoperative mortality in minority patients.

\section{Study Limitations}

Although considerable information on several perioperative variables existed, there was a lack of detailed, disease-specific clinical information for the individual surgical procedures. Likewise, information was unavailable regarding the process of care, such as decision to operate, when to operate, and intraoperative and the postoperative care, which are some of the fac- tors that may determine postoperative outcome. Similarly, we did not have information on surgical experience or hospital caseload, both of which are known to affect postoperative outcome. ${ }^{29}$

In addition, the anthropometric parameters used to calculate BMI for this study are self-reported values. Although directly measured height and weight values are preferable for calculating BMI, previous studies have shown that correlations between BMI based on measured height and weight and that based on selfreport are typically greater than $0.9 .{ }^{30}$ Given the reported strong correlation between self-reported and measured anthropometric parameters, the reporting error on the observed association between BMI and mortality in our study is likely minimal. The limitations of BMI as a measure of adiposity is well described. ${ }^{31,32}$ This study had no information on body fat distribution, which has been shown to have a direct correlation with mortality when BMI did not. ${ }^{33}$ Additionally, documented weight may be less accurate in the extremely obese group in that they may not have been weighed, either at home or in the hospital, due to lack of adequate weighing scales.

\section{Conclusions}

This study demonstrated that among minority surgical patients, higher BMI categories were associated with lower risk of postoperative death. This relationship was maintained, even in patients who developed 1 or more postoperative major complications, such that obese and severely obese patients had better survival compared with underweight and healthy weight patients. Mechanisms underlying this paradoxical survival advantage deserve further elucidation. It is important to emphasize that our findings in no way diminish the long-term dangers associated with excessive adiposity, but may serve to discard the preconceived notions that overweight and obese minority patients have poorer outcome after surgery than lean patients.

Disclosure: Nothing to report.

\section{References}

1. Li C, Ford ES, McGuire LC, Mokdad AH. Increasing trends in waist circumference and abdominal obesity among US adults. Obesity. 2007;15:216-224.

2. Ogden CL, Carroll MD, Curtin LR, McDowell MA, Tabak CJ, Flegal KM. Prevalence of overweight and obesity in the United States, 1999-2004. JAMA. 2006;295:1549-1555.

3. Stansbury JP, Huanguang J, Williams LS, Vogel WB, Duncan PW. Ethnic disparities in stroke epidemiology, acute care, and post-acute outcomes. Stroke. 2005;36:374-387.

4. Stevens J, Keil JE, Rust PF, Tyroler HA, Davis CE, Gazes PC. Body mass index and body girths as predictors of mortality in black and white women. Arch Intern Med. 1992;152:1257-1262.

5. Durazo-Arvizu R, Cooper RS, Luke A, Prewitt T, Liao Y, McGee DL. Relative weight and mortality in U.S. blacks and whites: findings from representative national population samples. Ann Epidemiol. 1997;7:383-395.

6. Calle EE, Thun MJ, Petrelli JM, Rodriguez C, Heath CW Jr. Bodymass index and mortality in a prospective cohort of U.S. adults. N Engl J Med. 1999;341:1097-1105. 
7. Stevens J, Keil JE, Rust PF, et al. Body mass index and body girths as predictors of mortality in black and white men. Am J Epidemiol. 1992;135:1137-1146.

8. Chapman GWJr, Mailhes JB, Thompson HE. Morbidity in obese and non-obese patients following gynecologic surgery for cancer. J Natl Med Assoc. 1988;80:417-420.

9. Fasol R, Schindler M, Schumacher B, et al. The influence of obesity on perioperative morbidity: retrospective study of 502 aortocoronary bypass operations. Thorac Cardiovasc Surg. 1992;40: $126-129$.

10. Nafiu OO, Shanks AM, Hayanga AJ, Tremper KK, Campbell DA Jr. The impact of high body mass index on postoperative complications and resource utilization in minority patients. I Natl Med Assoc. 2011;103:9-15.

11. Khuri SF, Henderson WG, Daley J, et al. The patient safety in surgery study: background, study design, and patient populations. J Am Coll Surg. 2007;204:1089-1102.

12. Davis CL, Pierce JR, Henderson W, et al. The assessment of the reliability of data collected for the Department of Veterans Affairs' National Surgical Quality Improvement Program (NSQIP). J Am Coll Surg. 2007;204:550-560.

13. Expert Panel on the Identification, Evaluation, and Treatment of Overweight in Adults. Clinical guidelines on the identification, evaluation, and treatment of overweight and obesity in adults: executive summary. Am J Clin Nutr. 1998;68:899-917.

14. Silber JH, Williams SV, Krakauer H, Schwartz JS. Hospital and patient characteristics associated with death after surgery: a study of adverse occurrence and failure to rescue. Med Care. 1992;30: 615-629.

15. Hair JF, Anderson RE, Tatham RL, Black WC. Multivariate Data Analysis. 5th ed. London: Prentice Hall International; 1998.

16. Manson JE, Bassuk SS, Hu FB, Stampfer MJ, Colditz GA, Willett WC. Estimating the number of deaths due to obesity: can the divergent findings be reconciled? I Women's Health. 2007;16(2): 168-176.

17. Ajani UA, Lotufo PA, Gaziano JM, et al. Body mass index and mortality among US male physicians. Ann Epidemiol. 2004;14/10: $731-739$.

18. Mullen JT, Moorman DW, Davenport DL. The obesity paradox: body mass index and outcomes in patients undergoing non-bariatric general surgery. Ann Surg. 2009;250:166-172.

19. Davenport DL, Xenos ES, Hosokawa P, Radford J, Henderson WG, Endean ED. The influence of body mass index obesity status on vascular surgery 30-day morbidity and mortality. J Vasc Surg. 2009; 49:140-147.

20. Kalantar-Zadeh K, Horwich TB, Oreopoulos A, et al. Risk factor paradox in wasting diseases. Curr Opin Clin Nutr Metab Care. 2007; 10:433-442.

21. Horwich TB, Fonarow GC, Hamilton MA, et al. The relationship between obesity and mortality in patients with heart failure. J Am Coll Cardiol. 2001;38:789-795.

22. Horwich TB, Fonarow GC. Reverse epidemiology beyond dialysis patients: chronic heart failure, geriatrics, rheumatoid arthritis, COPD, and AIDS. Semin Dial. 2007;20:549-553.

23. Rauchhaus M, Coats AJ, Anker SD. The endotoxin-lipoprotein hypothesis. Lancet. 2000;356:930-933.

24. Szmitko PE, Teoh H, Stewart DJ, et al. Adiponectin and cardiovascular disease: state of the art? Am J Physiol Heart Circ Physiol. 2007; 292:H1655-H1663.

25. Lavie CJ, Osman AF, Milani RV, Mehra MR. Body composition and prognosis in chronic systolic heart failure: the obesity paradox. Am J Cardiol. 2003;91:891-894.

26. Ghaferi AA, Birkmeyer JD, Dimick JB. Variation in hospital mortality associated with inpatient surgery. N Engl I Med. 2009;361: 1368-1375.

27. Wienpahl J, Ragland DR, Sidney S. Body mass index and 15-year mortality in a cohort of black men and women. I Clin Epidemiol. 1990;43:949-960.

28. Sidney S, Friedman GD, Siegelaub AB. Thinness and mortality. Am J Public Health. 1987;77:317-322.

29. Birkmeyer JD, Dimick JB, Staiger DO. Operative mortality and procedure volume as predictors of subsequent hospital performance. Ann Surg. 2006;243:411-417.

30. Willett WC. Nutritional Epidemiology. 2nd ed. Monographs in Epidemiology and Biostatistics; vol 30. New York: Oxford University Press, 1998:514.

31. Folsom AR, Kushi LH, Anderson KE, et al. Association of general and abdominal obesity with multiple health outcomes in older women: the Iowa Women's Health study. Arch Intern Med. 2000; 160:2117-2128

32. Michels KB, Greenland S, Rosner BA. Does body mass index adequately capture the relation of body composition and body size to health outcomes? Am J Epidemiol. 1998;147:167-172.

33. Ferrannini E, Sironi AM, Iozzo P, Gastaldelli A. Intra-abdominal adiposity, abdominal obesity, and cardio-metabolic risk. Eur Heart J Suppl. 2008;10(suppl B):B4-10. 